\title{
61 \\ Distinguished experts panel: \\ Integrated management in a \\ virtual world
}

\author{
Chair: James HERMAN, Vice President of Northeast \\ Consulting Resources, Inc., U.S.A. \\ Panelists: $\quad$ Keith WILLETTS, TCSI Corporation, U.S.A. \\ Brent BILGER, Cisco Systems, U.S.A. \\ Timothy HINDS, U.S. Environmental Protection Agency, \\ U.S.A. \\ Yogesh GUPTA, Computer Associates, U.S.A.
}

The panel discussion addresses IM '97's theme, "Integrated Management in a Virtual World," reflecting our increasing interest in overall management solutions applied across all types of networks, enterprise connection systems, distributed computing systems and applications. It continues to move our attention beyond the purely technical to focus on real and virtual, comprehensive management solutions in a world increasingly filled with virtual corporations, virtual LANs, inter-enterprise networking, real and virtual service management, outsourcing, and electronic commerce.

Each of the panelists will address different aspects of the complexity of management in an increasingly virtual environment. 